\title{
PENGARUH BRAND AMBASSADOR, BRAND IMAGE DAN BRAND AWARENESS TERHADAP PURCHASE DECISION
}

\author{
Rivan Christian Hariyanto ${ }^{1}$, Andi Wijaya ${ }^{2}$ \\ ${ }^{1}$ Program Studi Manajemen, Fakultas Ekonomi dan Bisnis, Universitas Tarumanagara \\ Email: rivan.115170479@stu.untar.ac.id \\ ${ }^{2}$ Program Studi Manajemen, Fakultas Ekonomi dan Bisnis, Universitas Tarumanagara* \\ Email: andiw@fe.untar.ac.id \\ *Penulis Korespondensi
}

Masuk : 02-08-2021, revisi: 15-08-2021, diterima untuk diterbitkan : 30-08-2021

\begin{abstract}
ABSTRAK
Duta merek adalah alat yang digunakan oleh perusahaan untuk menyalurkan informasi dan mengomunikasikan tentang produk. Citra merek adalah sebuah gambaran atau proyeksi konsumen tentang merek. Kesadaran merek adalah seberapa paham atau pengetahuan tentang suatu produk. Keputusan pembelian adalah tindakan untuk memilih dan mengambil keputusan untuk membeli suatu merek. Penelitian ini bertujuan untuk mempelajari pengaruh dari duta merek, citra merek dan kesadaran merek terhadap keputusan pembelian Under Armour di Jakarta. Populasi dalam penelitian ini adalah para pembeli produk Under Armour. Teknik pemilihan sampel yang akan digunakan pada penelitian ini adalah non-probability sampling. Data yang telah diperoleh dengan menggunakan kuesioner melalui googleform. Hasil dalam penelitian ini menunjukkan bahwa duta merek dan kesadaran merek memiliki pengaruh positif dan signifikan terhadap keputusan pembelian sedangkan citra merek memiliki pengaruh positif tetapi tidak signifikan terhadap keputusan pembelian.
\end{abstract}

Kata Kunci: Duta Merek, Citra Merek, Kesadaran Merek, Keputusan Pembelian

\section{ABSTRACT}

Brand ambassadors are tools used by companies to channel information and communicate about products. Brand image is a picture or projection of consumers about the brand. Brand awareness is how much you understand or know about a product. Purchasing decisions are actions to choose and make decisions to buy a brand. This study aims to study the influence of brand ambassadors, brand image and brand awareness on Under Armor purchasing decisions in Jakarta. The population in this study are the buyers of Under Armor products. The sampling technique used in this research is non-probability sampling. The data has been obtained by using a questionnaire via googleform. The results in this study indicate that brand ambassadors and brand awareness have a positive and significant influence on purchasing decisions while brand image has a positive but not significant effect on purchasing decisions.

Keywords: Brand Ambassador, Brand Image, Brand Awareness, Purchase Decision

\section{PENDAHULUAN}

\section{Latar Belakang}

Dalam lingkungan persaingan yang ketat sekarang ini, kesadaran yang dimiliki oleh konsumen seharusnya meningkat terhadap produk yang dipasarkan oleh perusahaan yang memproduksi produk tersebut. Perusahaan itu harus bisa menyenangkan konsumen dalam hal pelayanan seperti aktif berkomunikasi di aplikasi media sosial atau dari kualitas barang yang tinggi tetapi dengan harga yang terjangkau.

Lingkungan persaingan yang ketat juga mempengaruhi produk-produk olahraga, seperti Under Armour. Under Armour adalah sebuah perusahaan asal Amerika yang memproduksi pakaian dan perlengkapan untuk konsumen beraktivitas olah raga seperti sepatu, baju dan celana. Under 
Armour juga menyediakan aksesoris seperti topi, sarung tangan, tas, kaus kaki, masker olahraga dan lain-lain. Kantor Under Armour berpusat di Baltimore, Amerika Serikat dan memiliki kantor tambahan di Amsterdam, Jakarta, Hongkong, London, Munich, Panama City, Mexico City, dan lain-lain.

Pada awalnya Under Armour hanya berkembang dari sepatu olahraga yang dipakai oleh atlet di lapangan basket. Sekarang, mulai melebar ke olahraga lain seperti, lari, tennis dan lain-lain. Tidak seperti pesaing yang memposisikan tidak hanya di sepatu olahraga melainkan sepatu street.

Dari gambar di atas diketahui pertumbuhan sportwear merek Under Armour dari tahun 2011 sampai tahun 2019 terus mengalami penurunan sampai mencapai di bawah PDB dunia pada tahun 2019, tidak seperti para pesaingnya seperti Nike, Adidas, Puma dan Skechers yang berada di atas PDB dunia, maka dari itu peneliti akan menggunakan merek Under Armour sebagai objek penelitian ini.

Keputusan pembelian merupakan suatu kegiatan yang dilakukan tepat sebelum membeli barang. Pengertian keputusan pembelian menurut Schiffman \& Kanuk (2000: 437) adalah "the selection of an option from two or alternative choice". Keputusan pembelian yaitu kondisi dimana konsumen harus mengambil keputusan untuk membeli suatu produk diantara beberapa produk merek lainnya. Lalu menurut Kotler \& Keller (2012) "The purchase decision is a process that is contained of several stages which consumers do before purchasing a product". Keputusan pembelian adalah suatu proses yang terdiri dari beberapa tahap terdahulu yang dilakukan oleh konsumen sebelum konsumen memutuskan untuk melakukan pembelian terhadap suatu produk.

Menurut Woo (2019) “Consumers can recognize a product, evaluate quality, reducing purchase risk, and get experience and satisfaction from some product differentiation". Konsumen dapat mengenali suatu produk, mengevaluasi kualitas produk, mengurangi resiko pembelian serta mendapatkan pengalaman dan kepuasan dari beberapa diferensiasi produk. Ketika konsumen tidak memliki pengalaman atau kepuasan dari suatu produk, maka konsumen lebih memilih dengan produk yang dikenal banyak orang. Hal ini juga dapat mendorong perusahaan untuk memperkuat posisinya untuk menciptakan brand image dan brand ambassador yang positif di benak konsumen karena dari brand image dari produk itu sendiri.

\section{Brand Ambassador}

"A brand ambassador is a person who supports a brand from various famous public figures, apart from popular society can also be supported by ordinary people" (Nurhasanah, et. al., 2020). A brand ambassador can be used as a reference for consumer ratings and perceptions of a brand as a whole (Mudzakir, 2018). Brand ambassadors are cultural icons or, where they act as marketing tools that represent the individualism of human glory and the commodification and commercialization of a product (Gita dan Setyorini, 2016). Berdasarkan uraian di atas, hipotesis yang diusulkan adalah:

H1. Terdapat pengaruh brand ambassador terhadap purchase decision Under Armour di Jakarta.

\section{Brand Image}

Brand image is the perceptions and beliefs held by consumers, as reflected in the associations held in consumer memory (Keller dalam Wang dan Hariandja, 2016). Brand image also called schematic brand memory, contain an interpretation of the target market about the product characteristic, product benefit, usage situation, and market characteristic (Dewi, Edyanto, dan 
Siagan, 2020). Citra merek adalah persepsi konsumen tentang suatu merek sebagai refleksi dari asosiasi yang ada pada pikiran konsumen (Kotler dan Keller, 2016). Brand Image merupakan gabungan dari ingatan-ingatan mengenai brand yang tercipta dan membekas dibenak konsumen (Oscar \& Keni, 2019). Berdasarkan uraian di atas, hipotesis yang diusulkan adalah:

H2. Terdapat pengaruh brand image terhadap purchase decision Under Armour di Jakarta

\section{Brand Awareness}

Brand awareness is an intangible asset, which includes the brand, perceived quality, name or image, symbols and slogans of a brand which are the main source of competitive advantage in the future (Aaker dalam Octaviani dan Sumitro, 2020). Brand awareness is the consumer's ability to identify the brand in a different condition, which is reflected by brand recognition or recall performance. And the ability to occur in the consumer's mind when the consumer is thinking of some product and how easy the name occur (Dewi, Edyanto dan Siagan, 2020). Brand awareness is a capacity of a given customer to recognize or recall that a given brand belongs to a particular category of products (Romaniuk, Wight, \& Faulkner, 2017). Brand Awareness merupakan kempauan konsumen untuk mengenali dan mengingat kembali sebuah merek dengan cukup rinci untuk melakukan pembelian (Chandra \& Keni, 2019). Berdasarkan uraian di atas, hipotesis yang diusulkan adalah:

H3. Terdapat pengaruh brand awareness terhadap purchase decision Under Armour di Jakarta

\section{Purchase Decision}

Consumer behavior is the study of how individuals, groups, and organizations select, buy, use, and dispose of goods, services, ideas, or experiences to satisfy their needs and wants (Kotler \& Keller, 2016). Purchasing decisions are an act of consumersto form references among brands in thechoice group and buy the most preferredproducts (Kotler \& Keller, 2016). Stated that consumer purchase decision is purchase the most preferred brand, the brand most likely to be purchased by consumers (Kotler dan Armstrong dalam Novansa dan Ali, 2017). Keputusan pembelian merupakan pertimbangan-pertimbangan yang dilakukan oleh konsumen dalam menyeleksi suatu produk sebelum melakukan pembelian (Oscar \& Keni, 2019).

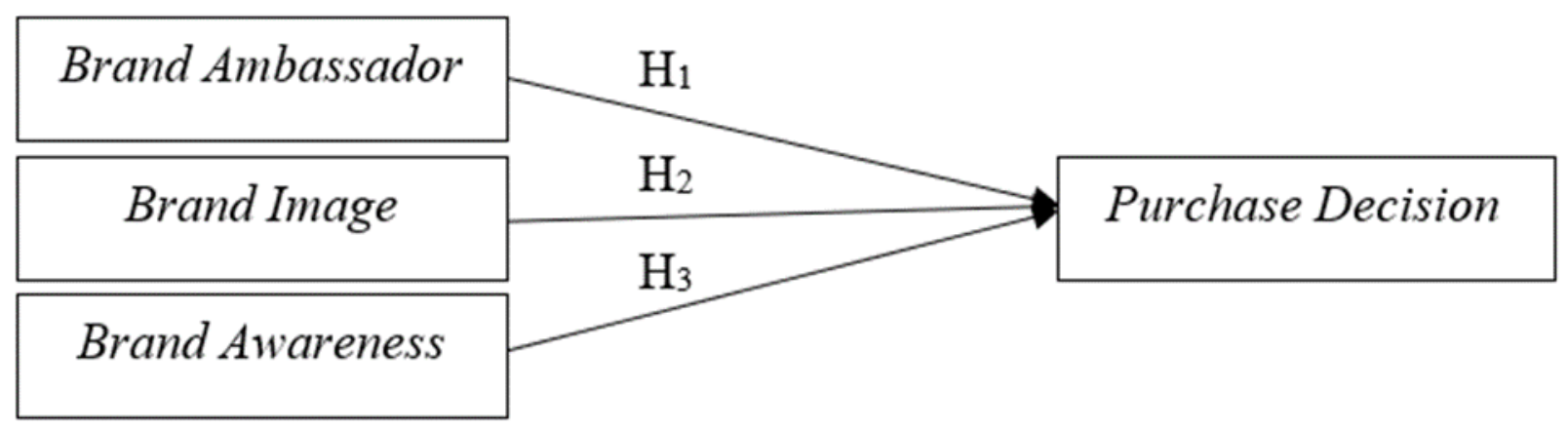

Gambar 1. Kerangka pemikiran

Berdasarkan kerangka pemikiran yang telah dibuat, maka dapat dibentuk hipotesis yang digunakan dalam penelitian sebagai berikut:

H1: brand ambassador memiliki pengaruh positif dan signifikan terhadap purchase decision.

$\mathrm{H} 2$ : brand image memiliki pengaruh positif dan signifikan terhadap purchase decision.

H3: brand awareness memiliki pengaruh positif dan signifikan terhadap purchase decision. 


\section{METODE PENELITIAN}

\section{Data dan Sampel}

Penelitian ini menggunakan desain penelitian deskriptif, dengan tujuan dapat membuat gambaran dan deskripsi secara akurat dan sistematis. Analisis data yang digunakan pada penelitian ini menggunakan Structural Equation Model - Partial Least Square dengan menggunakan aplikasi SmartPLS versi 3.3.3. Teknik pemilihan sampel pada penelitian ini, menggunakan nonprobability sampling - quota sampling. Jumlah sampel dalam penelitian ini berjumlah 100 orang. Metode pengumpulan data dalam penelitian ini menggunakan kuesioner melalui google form. Peneliti menyebarkan kusioner kepada subjek penelitian yaitu para pembeli produk Under Armour di Jakarta.

\section{HASIL DAN PEMBAHASAN}

\section{Karakteristik responden}

Ada beberapa karakteristik yang digunakan dalam penelitian ini. Karakteristik pertama, yaitu jenis kelamin yang terdiri dari 61 responden berjenis laki-laki (61\%) dan 39 responden berjenis perempuan (39\%). Karakteristik yang kedua, yaitu usia responden yang terdiri dari 4 responden dengan usia $<20$ tahun (4\%), 78 orang dengan usia 21-25 tahun (78\%), 12 responden dengan usia 26-30 tahun (12\%) dan 6 responden dengan usia >30 tahun (6\%). Karakteristik yang ketiga, yaitu pengeluaran yang terdiri dari 15 orang dengan pengeluaran $<\mathrm{Rp} .1 .000 .000(15 \%), 43$ orang dengan pengeluaran Rp. 1.000 .000 - Rp. 2.999 .999 (43\%), 27 responden dengan pengeluaran Rp. 3.000 .000 - Rp. 4.999 .999 (43\%) dan 15 responden dengan pengeluaran > Rp. $5.000 .000(15 \%)$. Karakteristik keempat, yaitu domisili yang terdiri dari 36 responden dengan domisili Jakarta Utara (36\%), 45 respoden dengan domisili Jakarta Barat (45\%), 7 responden dengan domisili Jakarta Pusat (7\%), 6 responden dengan domisili Jakarta Timur (6\%) dan 6 responden dengan domisili Jakarta Selatan (6\%).

\section{Uji Validitas dan Reliabilitas}

Uji validitas yang akan digunakan di dalam penelitian ini dengan melihat nilai Outer Loadings. Pengertian Outer Loadings menurut Kumar dan Upadhaya (2019) yaitu data akan dinyatakan valid jika nilai outer loadings yang diperoleh dari indikator tersebut harus $\geq 0,70$. Data yang memiliki nilai outer loadings $<0,70$ akan dihapus dalam penelitian ini karena data tersebut dinyatakan tidak valid di dalam penelitian ini.

Tabel 1. Hasil Outer Loadings

\begin{tabular}{|l|c|c|c|c|c|c|c|}
\hline \multicolumn{2}{|c|}{ Brand Ambassador } & \multicolumn{2}{c|}{ Brand Image } & \multicolumn{2}{c|}{ Brand Awareness } & \multicolumn{2}{c|}{ Purchase Decision } \\
\hline BA1 & 0,744 & BI3 & 0,731 & BAW1 & 0,792 & PD2 & 0,737 \\
\hline BA2 & 0,775 & BI4 & 0,712 & BAW2 & 0,714 & PD3 & 0,836 \\
\hline BA3 & 0,728 & BI5 & 0,749 & BAW3 & 0,716 & PD4 & 0,749 \\
\hline BA4 & 0,718 & BI6 & 0,784 & BAW4 & 0,715 & PD5 & 0,733 \\
\hline BA5 & 0,737 & BI7 & 0,723 & BAW5 & 0,713 & PD6 & 0,789 \\
\hline \multicolumn{7}{|r|}{} & \multicolumn{7}{|l}{} & PD7 & 0,718 \\
\hline
\end{tabular}

Reliabilitas harus dilakukan di dalam penelitian untuk memastikan data yang didapat apakah sudah benar dan reliable atau belum. Penelitian ini akan menggunakan Composite Reliability (CR) dan Cronbach's Alpha (CA). Data akan dinyatakan reliable jika CR yang didapat $\geq 0,70$ dan data akan dinyatakan tidak reliable jika $\mathrm{CR}$ yang didapat $<0,70$. Untuk data $\mathrm{CA}$ akan dinyatakan reliable jika nilai CA yang diperoleh $\geq 0,70$ dan data akan dinyatakan tidak reliable jika nilai yang diperoleh $\mathrm{CA}<0,70$. Dari hasil uji reliabilitas dengan melihat nilai Composite Reliability (CR) dan Cronbach's Alpha (CA). 
Tabel 2. Hasil Composite Reliability

\begin{tabular}{|c|c|c|c|}
\hline Variabel & Composite Reliability & Nilai Minimum & Keterangan \\
\hline Brand Ambassador & 0,859 & 0,7 & Reliabel \\
\hline Brand Image & 0,858 & 0,7 & Reliabel \\
\hline Brand Awareness & 0,851 & 0,7 & Reliabel \\
\hline Purchase Decision & 0,892 & 0,7 & Reliabel \\
\hline
\end{tabular}

Tabel 3. Hasil Cronbach's Alpha

\begin{tabular}{|c|c|c|c|}
\hline Variabel & Cronbach Alpha & Nilai Minimum & Keterangan \\
\hline Brand Ambassador & 0,796 & 0,7 & Reliabel \\
\hline Brand Image & 0,794 & 0,7 & Reliabel \\
\hline Brand Awareness & 0,781 & 0,7 & Reliabel \\
\hline Purchase Decision & 0,854 & 0,7 & Reliabel \\
\hline
\end{tabular}

\section{Koefisien Determinasi $\left(\mathbf{R}^{2}\right)$}

Nilai $R$-square juga digunakan umtuk menghitung besarnya peranan atau pengaruh variabel bebas pada variabel tergantung. Koefisien determinasi dihitung dengan cara mengalikan R2 dengan $100 \%$ (Sarwono dan Budiono, 2012). Hasil uji koefisiensi determinasi $\mathrm{R}^{2}$ yang telah dilakukan mendapatkan hasil sebesar 0,592. Uji ini dilakukan untuk melihat pengaruh variabel laten eksogen dengan variabel laten endogen yang ada di penelitian ini terdapat pengaruh sebesar 59\% terhadap 3 variabel laten eksogen yaitu brand ambassador, brand image dan brand awareness dengan variabel laten endogen yaitu purchase decision dan sisanya sebesar $41 \%$ dipengaruhi oleh variabel laten eksogen lainnya yang tidak digunakan pada penelitian ini.

\section{Predictive Relevance $\left(\mathbf{Q}^{2}\right)$}

Uji Predictive Relevance $\left(\mathrm{Q}^{2}\right)$ dilakukan dengan menggunakan proses blindfolding, hasil uji pada penelitian ini sebesar 0,319 , dimana uji ini berguna untuk menunjukan seberapa baik observasi yang dilakukan di dalam penelitian ini. Nilai observasi di penelitian ini tergolong baik, karena nilai $\mathrm{Q}^{2}$ yang diperoleh lebih besar dari 0 .

\section{Goodness of Fit (GOF)}

$$
\frac{\sqrt{0.548+0.548+0.534+0.580 \times 0,592}}{4}=0,57
$$

Uji Goodness of Fit berguna untuk memvalidasi model struktural secara keseluruhan. Hasil uji goodness of fit pada penelitian ini sebesar 0,57, dimana model struktural yang digunakan memiliki tingkat kecocokan sebesar 57\%.

Tabel 4. Pengujian Hipotesis (Path Coefficient)

\begin{tabular}{|l|c|c|c|c|c|}
\hline & $\begin{array}{c}\text { Original Sample } \\
(\mathbf{O})\end{array}$ & $\begin{array}{c}\text { Sample Mean } \\
(\mathbf{M})\end{array}$ & $\begin{array}{c}\text { Standar Deviation } \\
(\text { STDEV })\end{array}$ & $\begin{array}{c}\boldsymbol{t} \text {-statistics } \\
(\mathbf{| O / S T D E V})\end{array}$ & $\boldsymbol{p}$-values \\
\hline$(\mathbf{B A})->(\mathbf{P D})$ & 0,204 & 0,207 & 0,095 & 2,140 & 0,033 \\
\hline$(\mathbf{B A W})->(\mathbf{P D})$ & 0,467 & 0,473 & 0,101 & 4,623 & 0 \\
\hline$(\mathbf{B I})->($ PD) & 0,225 & 0,221 & 0,124 & 1,818 & 0,070 \\
\hline
\end{tabular}

Hasil pengujian hipotesis ini, sebagai berikut: hipotesis pertama, H0 ditolak karena original sample dari BA -> PD memiliki nilai 0,204 karena jika >0 maka terdapat pengaruh positif, sedangkan untuk Nilai $T$ Statistics dan $P$ Values dari BA $\rightarrow$ PD yaitu 2,140 dan 0,033. $T$ Statistics dan $P$ Values akan dinyatakan signifikan apabila nilai $T$ Statistics yang diperoleh lebih 
besar dari 1,960 dan $P$ Values akan dinyatakan signifikan apabila nilai yang diperoleh lebih kecil dari 0,05

Hipotesis kedua, H0 diterima karena original sample dari BI -> PD 0,225 karena jika >0 maka terdapat pengaruh positif, sedangkan untuk Nilai T Statistics dan $P$ Values dari BI $\rightarrow>$ PD yaitu 1,818 dan 0.070 dinyatakan tidak signifikan karena nilai $T$ Statistic yang diperoleh tidak lebih besar dari 1,960 dan nilai $P$ Values yang diperoleh lebih besar dari 0.05 .

Hipotesis ketiga, H0 ditolak karena original sample dari BAW -> PD sebesar 0,467 karena jika $>0$ maka terdapat pengaruh positif, sedangkan untuk Nilai T Statistics dan $P$ Values dari BAW -> PD yaitu 4,623 dan 0, dinyatakan signifikan karena nilai $T$ Statistics yang diperoleh lebih besar dari 1,960 dan nilai $P$ Values yang diperoleh lebih kecil dari 0,05.

\section{Diskusi}

Hasil dari hipotesis pertama yang ditemukan dalam penelitian ini memiliki pengaruh positif dan signifikan dari brand ambassador terhadap purchase decision produk Under Armour di Jakarta. Memiliki pengaruh yang positif disini memiliki arti yaitu apabila brand ambassador mengalami kenaikan maka purchase decision akan mengikuti juga yaitu mengalami kenaikan juga. Kode indikator tertinggi yaitu BA5 yang memiliki arti bahwa purchase decision dapat meningkat karena brand ambassador Under Armour memiliki pengalaman sebagai bintang iklan.

Pengaruh signifikan di dalam penelitian ini berarti brand ambassador dapat memberikan dampak yang besar untuk purchase decision konsumen produk Under Armour di Jakarta. Signifikansi yang diperoleh dalam penelitian ini dapat terjadi karena data yang telah dikumpulkan telah berhasil membuktikan hipotesis yang dimiliki, data yang dipakai di dalam penelitian ini, didapatkan dari sampel yang memiliki aspek-aspek yang cocok untuk dijadikan sebagai responden di dalam penelitian ini. Signifikansi juga dapat terjadi karena adanya kecocokan teknik analisi yang dipakai untuk menganalisa brand ambassador terhadap purchase decision produk Under Armour di Jakarta.

Hasil dari hipotesis kedua yang ditemukan dalam penelitian ini memiliki pengaruh positif tetapi tidak signifikan dari brand image terhadap purchase decision produk Under Armour di Jakarta. Memiliki pengaruh yang positif di sini memiliki arti yaitu apabila brand image mengalami kenaikan maka purchase decision akan mengikuti juga yaitu mengalami kenaikan juga. Kode indikator tertinggi yaitu BI6 yang memiliki arti bahwa purchase decision dapat meningkat karena merek Under Armour memiliki packaging yang unik.

Pengaruh yang tidak signifikan di dalam penelitian ini berarti brand image tidak dapat memberikan dampak yang besar untuk purchase decision konsumen produk Under Armour di Jakarta. Tidak signifikannya dalam hipotesis penelitian ini disebabkan dengan adanya perbedaan objek penelitian dari penelitian sebelumnya yang relevan dengan objek yang ada di penelitian ini. Objek pada penelitian sebelumnya yang relevan memakai objek pada industri kecantikan shampoo Pantene, berbeda dengan objek di dalam penelitian ini yaitu industri perlengkapan olahraga dengan merek Under Armour. Pada penelitian sebelumnya yang relevan juga terdapat perbedaan domisili, domisili yang dipakai dalam penelitian sebelumnya yang relevan memakai domisili Surabaya sedangkan domisili yang dipakai dalam penelitian ini memakai domisili Jakarta. 
Hasil dari hipotesis ketiga yang ditemukan dalam penelitian ini memiliki pengaruh positif dan signifikan dari brand awareness terhadap purchase decision produk Under Armour di Jakarta. Memiliki pengaruh yang positif di sini memiliki arti yaitu apabila brand awareness mengalami kenaikan maka purchase decision akan mengikuti juga yaitu mengalami kenaikan juga. Kode indikator tertinggi yaitu BAW1 yang memiliki arti bahwa purchase decision dapat meningkat karena konsumen mengenali merek Under Armour dibandingkan merek lain dengan mudah.

Pengaruh signifikan di dalam penelitian ini berarti brand awareness dapat memberikan dampak yang besar untuk purchase decision konsumen produk Under Armour di Jakarta. Signifikansi yang diperoleh dalam penelitian ini dapat terjadi karena data yang telah dikumpulkan telah berhasil membuktikan hipotesis yang dimiliki, data yang dipakai di dalam penelitian ini, didapatkan dari sampel yang memiliki aspek-aspek yang cocok untuk dijadikan sebagai responden di dalam penelitian ini. Signifikansi juga dapat terjadi karena adanya kecocokan teknik analisi yang dipakai untuk menganalisa brand ambassador terhadap purchase decision produk Under Armour di Jakarta.

\section{KESIMPULAN DAN SARAN}

Berdasarkan hasil penelitian yang telah dilakukan bahwa pengaruh brand ambassador dan brand awareness memiliki pengaruh positif dan signifikan, sedangkan brand image memiliki pengaruh positif tetapi tidak signifikan terhadap purchase decision. Saran bagi penelitian yang akan datang, disarankan untuk menambah jumlah sampel untuk bisa menggambarkan keadaan yang sebenarnya. Lalu, memperbesar cakupan wilayah yang tidak terdiri dari 1 wilayah saja, tentu saja untuk bisa menggambarkan keadaan yang sesungguhnya. Serta, memperbanyak jumlah variabel eksogen untuk penelitian yang akan datang, berguna untuk meningkatkan keakuratan hasil penelitian

\section{REFERENSI}

Chandra, C., \& Keni, K. (2019). Pengaruh Brand Awareness, Brand Association, Perceived Quality, Dan Brand Loyalty Terhadap Customer Purchase Decision. Jurnal Muara Ilmu Ekonomi Dan Bisnis, 3(1), 176. https://doi.org//10.24912/jmieb.v3i1.3506

Dewi, L. G. P. S., Edyanto, N., \& Siagian, H. (2020). The Effect of Brand Ambassador, Brand Image, and Brand Awareness on Purchase Decision of Pantene Shampoo in Surabaya, Indonesia. SHS Web of Conferences, 76(11), 01023.

Gita, D., \& Setyorini, R. (2016). Pengaruh Brand Ambassador terhadap Brand Image Perusahaan Online zalora.co.id. E-Proceeding of Management, 3(3), 620-626.

Kotler, P. \& K. L. Keller. (2012). Marketing Management, 14th edition, Pearson Prentice Hall, New Jersey.

Kotler, Philip \& Kevin Lane Keller, (2016). Marketing Management, Edisi 15. Pearson Pretice Hall, New Jersey

Kumar, S., \& Upadhaya, D. G. (2019). Impact of Corporate Credibility, Brand Awareness, Brand Image and Brand Loyalty on Purchase Intention in the Telecommunication Sector of Karachi. Journal of Indonesian Economy and Business, 12(1), 508-524.

Mudzakir, F. (2018). the Influence of Brand Ambassador Usage Toward Brand Image of Oppo. Industrial Research Workshop and National Seminar, 648-655.

Novansa, H., \& Ali, H. (2017). A study on Demonetization and its Impact on Corruption and Black Money. Saudi Journal of Humanities and Social Sciences, 2(5), 597-610.

Nurhasanah, et. al. (2020). The Effect of E-WOM , Brand Trust , and Brand Ambassador on Purchase Decisions at Tokopedia Online Shopping Site. International Conference on Advanced Science and Technology. 
Octaviani, N. W., \& Sumitro, D. (2020). Influence of Lifestyle, Halal Labels, Brand Ambassadors, and Brand Awareness on Purchasing Decisions (Case Study at Pamulang Beautiful Light Shop , Tangsel). Indonesian College of Economic, 16, 1-16.

Oscar, Y., \& Keni, K. (2019). Pengaruh Brand Image, Persepi Harga, Dan Service Quality Terhadap Keputusan Pembelian Konsumen. Jurnal Muara Ilmu Ekonomi Dan Bisnis, 3(1), 20. http://dx.doi.org/10.24912/jmieb.v3i1.3300

Sarwono, Jonathan dan Budiono, Herlina. (2012). Statistika Terapan: Aplikasi (Untuk Riset Skripsi, Tesis dan Disertasi Menggunakan SPSS, AMOS dan Excel). Jakarta: PT Elex Media Komputindo.

Schiffman and Lazar Kanuk. (2000). Costumer behavior. International Edition. Prentice Hall.

Wang, F., \& Hariandja, E. S. (2016). The Influence of Brand Ambassador on Brand Image and Consumer Purchasing Decision: A Case of Tous Les Jours in The Influence of Brand Ambassador on Brand Image and Consumer Purchasing Decision: local or international brands in the market market in Indonesia. International Conference Od Enterpreneurship, March, 292-30

Woo, H. (2019). The Expanded Halo Model of Brand Image, Country Image and Product Image in The Context of Three Asian Countries. Asia Pacific Journal of Marketing and Logistics, 31(4), 773-790. 